\section{The passage of food through the gut of rats and its uptake of fluid'}

KEITH OATLEY and F. M. TOATES, Laboratory of Experimental Psychology, University of Sussex, Brighton, England

Stomachs and small intestines were examined and weighed up to $6 \mathrm{~h}$ after rats had been allowed to eat for $30 \mathrm{~min}$ without water available. A meal of commercial rat food left the stomach with a time constant of about $4 \mathrm{~h}$. Each gram of food eaten attracted approximately $1 \mathrm{ml}$ of additional fluid into the gut. The time course of this fluid movement and of electrolyte absorp tion is such that much of the drinking associated with meals in conditions of ad lib intake of food and water seems to be in anticipation of changes in the body fluids, rather than in response to them.

In developing an understanding of the mechanisms by which drinking contributes to the regulation of water balance, a model of thirst (Oatley, 1967) has been described and is being extended. For the model to be embodied in a computer simulation, quantitative measurements of the time course of relevant events need to be made. Since an important stimulus of drinking is the eating of dry food, it is necessary to know what body-fluid changes a meal produces, and whether these changes can account for the drinking that accompanies meals.

Fundamental work on this problem was performed by Lepkovsky, Lyman, Fleming,
Nagumo, \& Dimick (1957). They determined the amount of water and food in rats' alimentary tracts at intervals up to $11 \mathrm{~h}$ after allowing them to eat. They found that the ratio of food to water in the gut was constant, and unaltered by whether or not rats were allowed to drink while eating. If water was not available from drinking, it entered the gut from the bloodstream, and this loss of water from body fluids might well stimulate drinking. There are, however, some inadequacies in the data of Lepkovsky et al. They allow rats to eat for $2 \mathrm{~h}$ before making their first measurements. Also, some control values are difficult to ex tract from their graphs, and they do not give the water content of the food they used. These factors made it difficult to assess the quantity of water leaving the body fluids, or the time course of this process. Our experiment makes it possible to estimate these essential variables.

\section{METHOD}

Subjects were 28 male hooded rats with a mean weight of $349 \mathrm{~g}$ at the start of the experiment. They were adapted to a $231 / 2-h$ food-deprivation schedule for 4 days with water available at all times. On the test day, starting $1 \frac{1}{2} \mathrm{~h}$ before its $30-\mathrm{min}$ eating period, each rat was also deprived of water. Food eaten was carefully measured to the nearest $0.1 \mathrm{~g}$, not neglecting spillage. Rats were killed by an intracardiac injection of Nembutal either before eating, or at intervals up to $6 \mathrm{~h}$ after the end of eating.

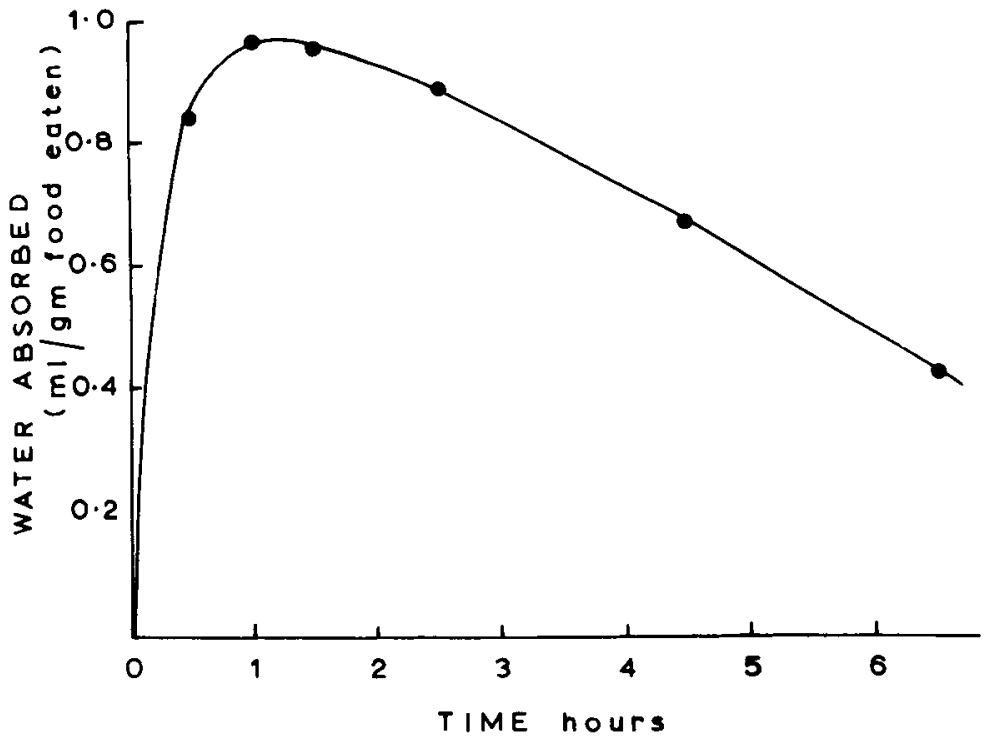

The abdominal cavity was immediately opened, and ligatures quickly tied at the lower end of the oesophagus, the pylorus, and the junction of the ileum and caecum. The stomach and small intestine were then carefully stripped from their mesentery and weighed separately to the nearest $0.01 \mathrm{~g}$. These organs were then dried to constant weight in an oven at $105 \mathrm{deg} C$.

The food used was Spillers Small Animal Diet, including $21 \%$ protein, $48 \%$ digestible carbohydrate, $5 \%$ oil, $0.3 \% \mathrm{Na}, 1.3 \% \mathrm{~K}$, $0.9 \% \mathrm{Ca}, 0.8 \% \mathrm{P}$, and $0.8 \%$ total chloride. The diet was said by the makers to contain $8.5 \%$ moisture, and we ground up some of this and found it to lose $6 \%$ of its weight in the drying procedure.

\title{
RESULTS
}

Four control rats, not allowed to eat, had stomachs of mean weight $1.72 \mathrm{~g}(0.52 \%$ body weight) immediately after removal, and $0.38 \mathrm{~g}$ after dehydration. Mean intestine weight was $5.27 \mathrm{~g}$ ( $1.62 \%$ body weight) on removal and $1.55 \mathrm{~g}$ when dried.

Experimental rats were allowed to eat for $30 \mathrm{~min}$ and four were examined at each of the following times after the end of eating: $0,0.5,1,2,4$, and $6 \mathrm{~h}$. The mean amount of food eaten was $5.7 \mathrm{~g}$.

Figure 1 shows the amount of fluid taken into the gut above the caecum. This was calculated by differences between wet and dried weights minus weights of control organs and reached a maximum of $0.97 \mathrm{ml} / \mathrm{g}$ of food eaten about $1 \mathrm{~h}$ after the beginning of eating. This indicates a time constant of fluid uptake of about 10 to $15 \mathrm{~min}$. It is unlikely to be shorter than 7 or longer than $20 \mathrm{~min}$. The points on the graph at the longer delays after eating might not represent all the fluid taken into the gut in response to the meal since some food with its associated fluid will have reached the large intestine.

Figure 2 shows the rate of clearance of food from the stomach, expressed as a percentage of the original meal. These stomachs were all distended with a relatively solid mass of food. Only when the food had passed into the intestine did it become semi-fluid. The time constant of food leaving the stomach was of the order of $4 \mathrm{~h}$, consistent with the data of Lepkovsky et al (1957). We also confirm that the proportion of the meal in the small intestine stayed relatively constant during $6 \mathrm{~h}$ (between $9 \%$ and $18 \%$ ), and that after equilibration, for approximately $1 \mathrm{~h}$ the ratio of food to water in the upper gut stayed constant.

DISCUSSION

Our results allow calculation of the time course and quantity of the water that is lost

Fig. 1. Mean water taken into the upper gut in response to a meal of dry food that started at time $=0$ and lasted $30 \mathrm{~min}$. 


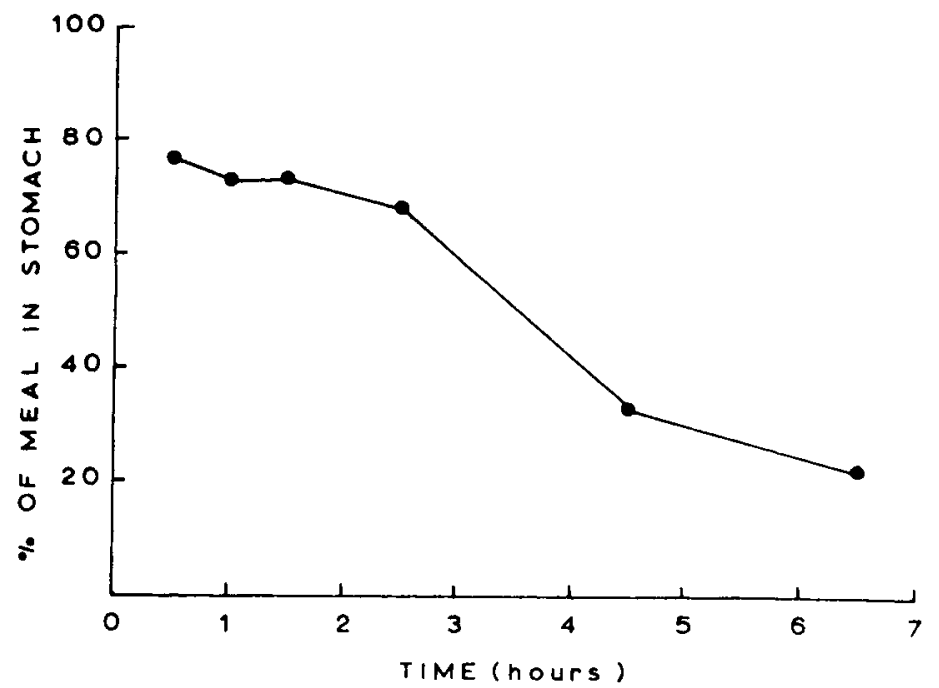

from the body fluids as a result of a meal. The estimate of a time constant of 10 to $15 \mathrm{~min}$ agrees closely with the measurements made by Novin (1962) of the increase in tissue conductivity following a meal. Inspection of his data allows an estimate of 10 to $12 \mathrm{~min}$ to be made for this time constant. Though Novin does not give the amount of food eaten, it is unlikely that the rat for which he presents data would have eaten more in $20 \mathrm{~min}$ than our rats did in $30 \mathrm{~min}$. Hence it is possible to calculate a maximum increase in total osmotic pressure produced by a meal of dry food. For a 300-g rat, eating $5.7 \mathrm{~g}$ of food, the maximum increase in osmotic concentration produced by fluid entering the gut, if it were water, would be a little less than $3 \%$. In fact, some of this fluid will be saliva and digestive juices at near isotonic concentration and this experiment does not allow separation of digestive juices from water osmotically attracted into the gut. Absorption into the blood of electrolytes from the food would probably not increase osmotic pressure by more than another $3 \%$. This is because absorption of these substances does not take place from the stomach to any extent, but from the small intestine. A total increase in electrolyte concentration combining both factors might perhaps be $6 \%$, as compared to the $10 \%$ conductivity change found by Novin.

Novin unfortunately has made no such calibration of his results, but a factor of about 2, relating per cent change of conductivity and effective osmotic pressure, would also account for Novin's conductivity measurements following an injection of $\mathrm{NaCl}$, and for the comparison of his conductivity changes of about $5 \%$ following
$48 \mathrm{~h}$ of water deprivation with the increase in serum sodium concentration of $2.9 \%$ found by Fitzsimons \& Oatley (1967) under similar conditions. Novin does consider this point in relation to the decreases in conductivity that he observed when rats drank water. He calculates that drinking a quantity of water equivalent to $2 \%$ body weight should decrease total fluid osmotic pressure by $3 \%$ when fully distributed. The observed change in conductivity was $5.7 \%$, and he supposed that the discrepancy was due to incomplete equilibration between cellular and extracellular compartments. This is unlikely since complete mixing of water injected into the blood has been found by a number of authors (e.g., Hevesy \& Jacobsen, 1940) to be complete in $30 \mathrm{~min}$, a time constant of about $6 \mathrm{~min}$. More probably, as elsewhere the per cent change in conductivity is twice the per cent change in electrolyte osmotic pressure.

Absorption of electrolytes contained in the food, osmotic movement of water into the gut, and secretion of isotonic digestive juices could all contribute to a thirst that would explain drinking in terms of 1 to $2 \mathrm{ml}$ of water being needed with each gram of food eaten.

Further, as Lepkovsky et al (1957) point out, the preferred source of this fluid is from drinking. This fits very well with data on ad lib food and water intake. For instance, Fitzsimons \& Le Magnen (1968) found that $1.3 \mathrm{ml}$ of water were associated with each gram of a standard rat diet eaten in ad lib conditions. What does not fit simple homeostatic principles so easily is the time course of meal-associated drinking. Fitzsimons and Le Magnen note that a significant proportion of water is taken
Fig. 2. Mean percentage of a 30-min meal remaining in the stomach as a function of time since the beginning of eating.

immediately before meals, using this anticipation of eating as additional evidence for their hypothesis that food-associated drinking is a learned response. Oatley (1965) found that the proportion of bouts of drinking that occur $15 \mathrm{~min}$ or less before meals is between $20 \%$ and $30 \%$ in stable ad lib conditions. Furthermore, even the drinking that follows a meal may anticipate the time course of the body fluid changes associated with the meal. Oatley (1965) found that between $40 \%$ and $55 \%$ of drinks occurred during a meal or within $5 \mathrm{~min}$ of the end of one. The time constant of the body fluid changes as measured here and by Novin indicate that less than half of the full effect of the meal would have occurred in this time. A similar anticipation of the effects of meals in doves has been suggested by McFarland (1969). Though the quantity of water drunk with a meal closely matches fluid changes that would be produced by the meal, this drinking in ad lib conditions seems to take place instead of a body fluid change rather than in response to it.

\section{REFERENCES}

FITZSIMONS, J. T., \& LE MAGNEN, J. Eating as a regulatory control of drinking. Joumal of Comparative \& Physiological Psychology, 1969, 67, 273-283.

FITZSIMONS, J. T., \& OATLEY, K. Additivity of stimuli for drinking in rats. Journal of Comparative \& Physiological Psychology, 1968, 66, 450-455.

HEVESY, G., \& JACOBSEN, C. F. Rate of passage of water through capillary and cell walls. Acta Physiologica Scandinavica, 1940, 1, 11-18.

LEPKOVSKY, S., LYMAN, R., FLEMING, D. NAGUMO, M., \& DIMICK, M. Gastrointestinal regulation of water and its effect on food intake and rate of digestion. American Journal of Physiology, 1957, 188, 327-331.

McFARLAND, D. J. Mechanisms of behavioural disinhibition. Animal Behaviour, in press.

NOVIN, D. The relation between electrical conductivity of brain tissue and thirst in the rat. Journai of Comparative \& Physiological Psychology, 1962, 55, 145-154.

OATLEY, $\mathrm{K}$. Thirst and drinking mechanisms in the regulation of water intake in rats. Unpublished doctoral dissertation, University of London, 1965.

OATLEY, $K$. A control model of the physiological basis of thirst. Medical \& Biological Engineering, 1967, 5, 225-237.

1. This investigation was supported in part by a postgraduate studentship from the S.R.C. to the second author. 